\title{
Numerical Simulation of the Storm Surge at the Sakhalin Island Southern Part on November 15, 2019
}

\author{
A. I. Zaytsev ${ }^{1, *}$, E. N. Pelinovsky ${ }^{2}$, D. Dogan ${ }^{3}$, B. Yalciner $^{3}$, \\ A. Yalciner $^{3}$, A. A. Kurkin ${ }^{4}$, A. A. Moskvitin ${ }^{1}$ \\ ${ }^{1}$ Special Research Bureau for Automation of Marine Researches, Far Eastern Branch of Russian \\ Academy of Sciences, Yuzhno-Sakhalinsk, Russian Federation \\ ${ }^{2}$ Institute of Applied Physics, Russian Academy of Sciences, Nizhny Novgorod, Russian Federation \\ ${ }^{3}$ Middle East Technical University, Ankara, Turkey \\ ${ }^{4}$ Nizhny Novgorod State Technical University n. a. R. E. Alekseev, \\ Nizhny Novgorod, Russian Federation \\ * aizaytsev@mail.ru
}

Purpose. Investigation of the storm surge in Korsakov in the southern part of the Sakhalin Island on November 15, 2019 and comparison of the results of its numerical simulation with the data of in situ measurements constitute the aim of the article.

Methods and Results. In situ measurements of the storm surge in Korsakov (the Sakhalin region) were performed and the data on the flooded area dimensions were collected. A storm period on the Sakhalin Island is almost the annual event in an autumn-winter season. The severe storm that happened in the southern Sakhalin region on November 15, 2019 led to flooding of the port territory in Korsakov. Due to the NAMI-DANCE computational complex, the storm surge was numerically simulated within the framework of the system of shallow water equations in the spherical coordinates on the rotating Earth with the regard for the friction force and the atmospheric effect. The calculations included the data on temporal and spatial distribution of the wind speed at the altitude $10 \mathrm{~m}$ taken from the Climate Forecast System Reanalysis database. The data on the atmospheric pressure were not applied in simulations since the atmosphere pressure gradient at the area under study was small. The simulation was carried out in the course of three days. The simulations showed that in 20 hours after the wind forcing had started, the water level in the port increased up to its maximum values, and did not fall the whole day. The water level maximum heights were concentrated in the southwestern part of the Aniva Bay. At that the calculated current speeds reached $2 \mathrm{~m} / \mathrm{s}$. During the storm, at the wind speed up to $15 \mathrm{~m} / \mathrm{s}$, the storm surge height in the Korsakov port area constituted $1.7 \mathrm{~m}$, whereas the width of the flooded zone was up to $200 \mathrm{~m}$. These results are confirmed well by the in situ measurement data.

Conclusions. The simulation values of the power characteristics for the above-mentioned storm are represented in the paper. The Froude number square reaches 0.03 in the Korsakov city port area, and spatial distribution of the wave strength moment is up to $1 \mathrm{~m}^{3} / \mathrm{s}^{2}$. Field measurements and eyewitness reports confirm the evidence of a powerful impact of a storm surge upon the port constructions.

Keywords: storm surge, Sakhalin Island, numerical simulation, shallow water theory, in situ measurements.

Acknowledgments: the work was carried out with partial support of the RFBR grant No. 18-0580019 (Program "Dangerous Phenomena"), as well as with financial support of the grants of the President of Russian Federation on state support of leading scientific schools of Russian Federation NSh-2485.2020.5 and scientific research of young Russian scientists - doctors of sciences MD-148.2020.5.

For citation: Zaytsev, A.I., Pelinovsky, E.N., Dogan, D., Yalciner, B., Yalciner, A., Kurkin, A.A. and Moskvitin A.A., 2020. Numerical Simulation of the Storm Surge at the Sakhalin Island Southern Part on November 15, 2019. Physical Oceanography, [e-journal] 27(4), pp. 364-373. doi:10.22449/1573-160X-2020-4-364-373

DOI: $10.22449 / 1573-160 X-2020-4-364-373$

(C) A. I. Zaytsev, E. N. Pelinovsky, D. Dogan, B. Yalciner, A. Yalciner, A. A. Kurkin, A. A. Moskvitin, 2020

(C) Physical Oceanography, 2020 


\section{Introduction}

Storm surges are quite common at the Sakhalin coast, especially in its southern part [1-4]. The stormy period on Sakhalin is observed almost every year in the autumn-winter period. Severe storms often cause damage in the port of Korsakov. For instance, during the strongest surges in the south of the island in November 1990 and 1995, ships were thrown aground, hit the piers, drowned, a significant amount of cargo was washed into the sea or was spoiled by sea water. On 2 October 2015, as a result of a strong storm in the sea and a large surge wave, the territory of Korsakov seaport and Vokzalnaya station was flooded. The water level there reached $1 \mathrm{~m}$. The territory in the area of Yuzhny Mol (South Mole) was also flooded, the roads at the entrance to the Prigorodnoye port and on the Korsakov - Novikovo section were washed out. The most recent case of flooding occurred on 3 December 2019, when the Korsakov commercial port was affected by an intense storm and water flows flooded the territory of the enterprise and washed away into the sea several containers (Korsakov port was flooded again //SakhalinInfo:[website].2019.URL:https://sakhalin.info/search/181472?text=Korsa kovsky+commercial+port (Accessed: 09.07.2020)).

Here we are going to discuss the storm surge on 15 November 2019, when the cargo port in Korsakov was flooded and most of its territory was covered with water. According to eyewitnesses, at first the water left, and then came ashore. The vessels left the port in advance. During the next day the port did not carry out any unloading and loading operations, and intense waves were observed in its water area (Korsakov port went under water // Korsakov: [website]. 2019. URL: https://korsakov.sakh.com/news/korsakov/180441 (Accessed: 09.07.2020)).

The storms of such power occur in Korsakov several times a year and, as a rule, do not cause significant damage to infrastructure and property.

According to meteorological data from the web resource https://worldweather.ru, on 14 November, 2019, in the morning a strong southern and southeastern wind blew at a speed of $10-12 \mathrm{~m} / \mathrm{s}$, then in the afternoon the wind changed direction to the western; On November 15, without changing its direction, it increased to almost $17 \mathrm{~m} / \mathrm{s}$.

We organized a study of the flooding zone and measured the runup heights and the width of this zone in the coastal area of Korsakov. Numerical simulation of storm surges was carried out within the framework of the shallow water equations using the NAMI-DANCE computational complex. The results of calculating the storm surge power characteristics are also presented.

\section{The study of the flooding zone}

The storm surge on 15 November 2019 flooded the port area of Korsakov in the south of the Sakhalin region (Fig. 1), the flooding zone boundary is shown in Fig. 2. According to the measurement results, the width of the flooded zone from the water edge reached $200 \mathrm{~m}$.

During the study we carried out the measurements of the height which the water reached relative to sea level (the runup height), and the water level in some flooded points (Fig. 3). Note that the maximum runup height reached $1.7 \mathrm{~m}$ above the sea level. A significant part of the coastal area was flooded. Since the residential quarters of Korsakov are located on a hill, the water was unable to penetrate into them for a considerable distance. 


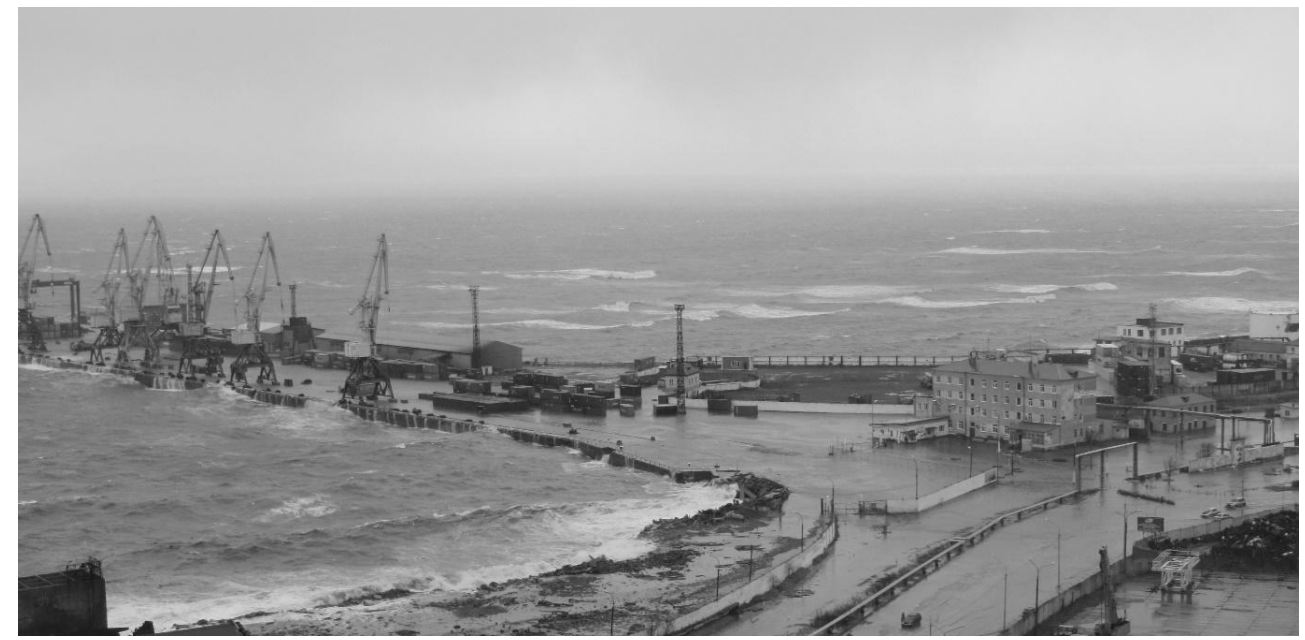

F i g. 1. Photo of the flooded part of the Korsakov port

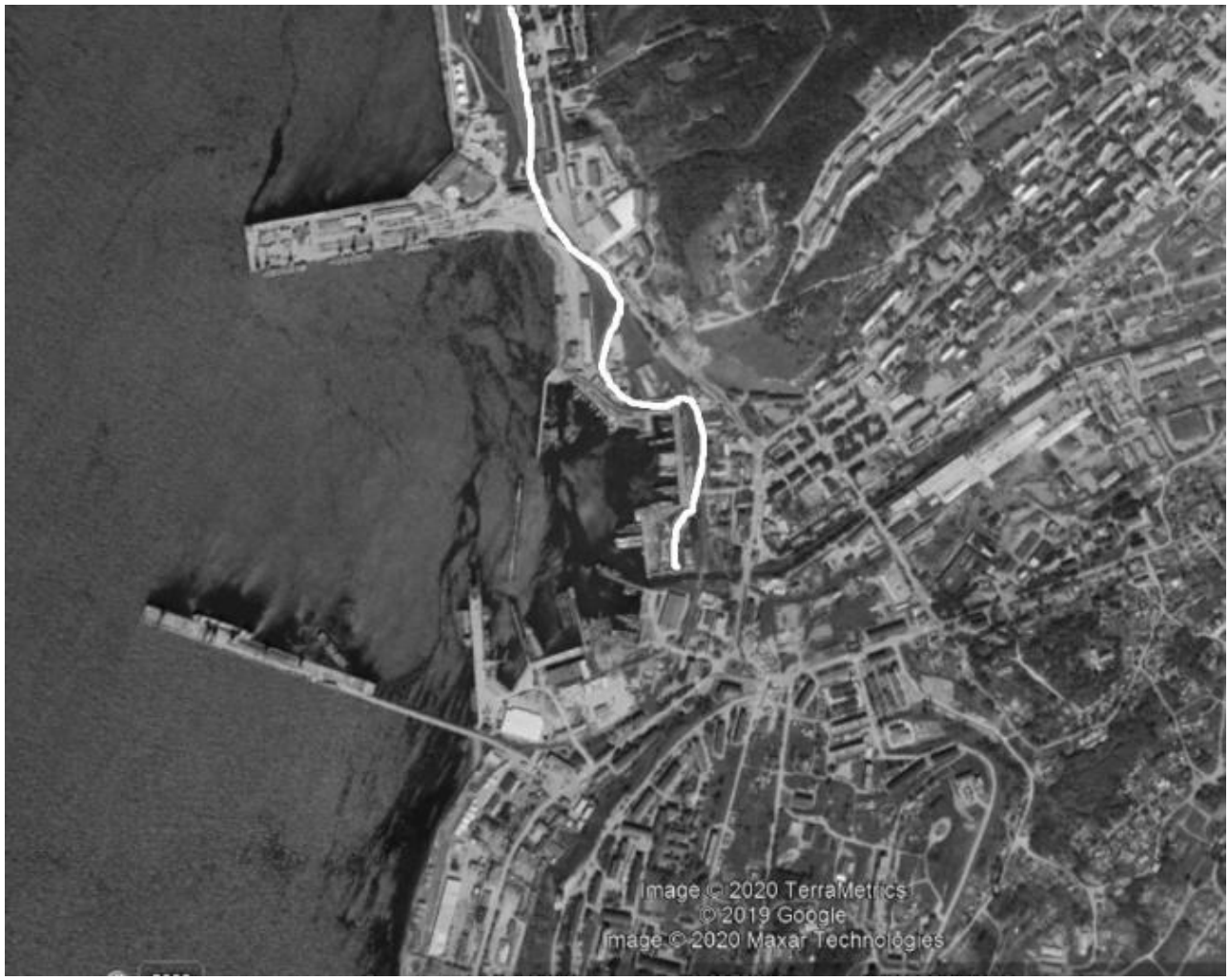

F i g. 2. Zone flooded due to the storm surge on 15.11.2019 (white line marks the GPS-track of the runup boundary) 

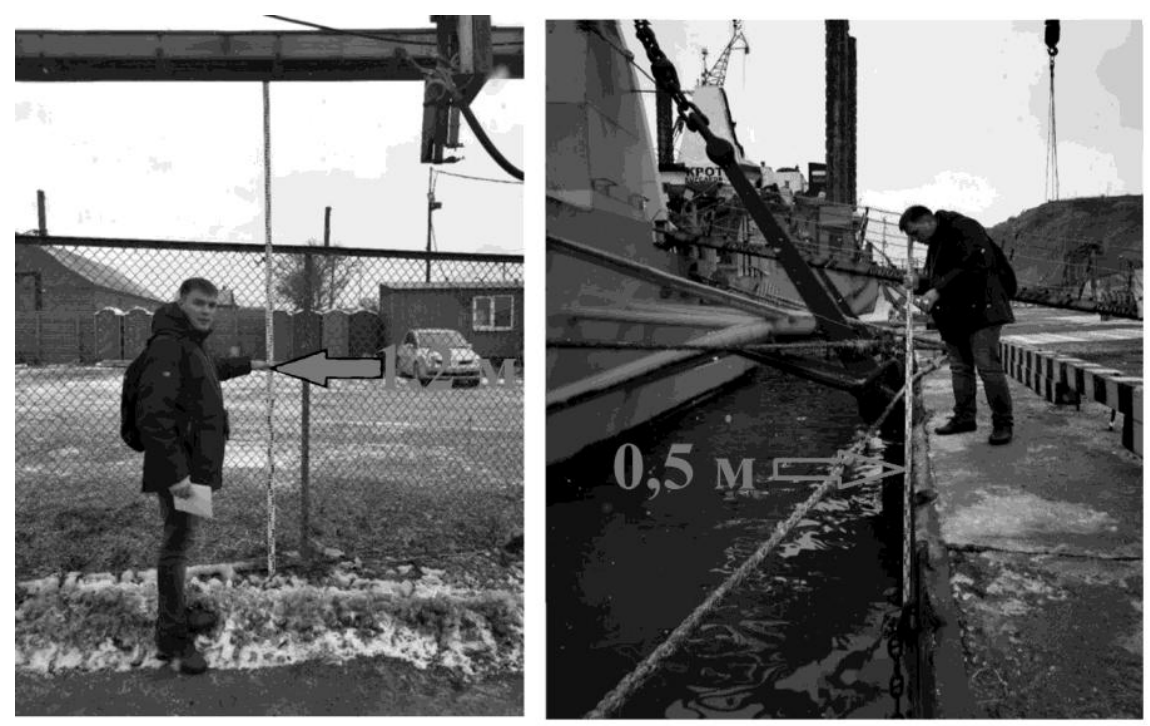

F i g. 3. Measurement of the runup height resulted from the storm surge in the port of Korsakov

\section{Storm surge numerical modeling}

Storm surges are caused by long waves, therefore they are usually modeled using shallow water equations. The literature on the calculation of storm surges is quite voluminous, and here we are to mention only a few works where storm surges were simulated in the seas surrounding Russia [5-8].

In our calculations we used the NAMI-DANCE_P computational complex $[9,10]$ based on solving a system of nonlinear shallow water equations in spherical coordinates, with regard to the Earth's rotation, friction force and atmospheric effect:

$$
\begin{gathered}
\frac{\partial M}{\partial t}+\frac{1}{R \cos \theta} \frac{\partial}{\partial \lambda}\left(\frac{M^{2}}{D}\right)+\frac{1}{R \cos \theta} \frac{\partial}{\partial \theta}\left(\frac{M N \cos \theta}{D}\right)+\frac{g D}{R \cos \theta} \frac{\partial \eta}{\partial \lambda}+ \\
+\frac{g n^{2}}{D^{7 / 3}} M \sqrt{M^{2}+N^{2}}-\frac{\rho_{a i r} C_{D}}{\rho_{w}} U_{w} \sqrt{U_{w}^{2}+V_{w}^{2}}=f N \\
\frac{\partial N}{\partial t}+\frac{1}{R \cos \theta} \frac{\partial}{\partial \lambda}\left(\frac{M N}{D}\right)+\frac{1}{R \cos \theta} \frac{\partial}{\partial \theta}\left(\frac{N^{2} \cos \theta}{D}\right)+\frac{g D}{R} \frac{\partial \eta}{\partial \theta}+ \\
+\frac{g n^{2}}{D^{7 / 3}} N \sqrt{M^{2}+N^{2}}-\frac{\rho_{a i r} C_{D}}{\rho_{w}} V_{w} \sqrt{U_{w}^{2}+V_{w}^{2}}=-f M \\
\frac{\partial \eta}{\partial t}+\frac{1}{R \cos \theta}\left[\frac{\partial M}{\partial \lambda}+\frac{\partial}{\partial \theta}(N \cos \theta)\right]=0
\end{gathered}
$$

Here $\eta$ is a water surface displacement; $t$ is time; $M$ and $N$ are the components of water discharge along the longitude $\lambda$ and latitude $\theta ; f$ is the Coriolis parameter ( $f=2 \Omega \sin \theta$ and $\Omega$ is the Earth rotation frequency); $R$ is the radius of the Earth; 
$D=h(x, y)+\eta$ is a total depth of the basin, $h(x, y)$ is a bottom relief; $g$ is a gravity acceleration; $\rho_{\text {air }}$ is air density; $\rho_{w}$ is water density; $U_{w}$ and $V_{w}$ are the wind velocity components (usually measured at $10 \mathrm{~m}$ height from the water surface); $C_{D}$ is a drag coefficient (in the calculation was taken as equal to $2 \cdot 10^{-3}$ ); $n$ is the bottom roughness coefficient (the so-called Manning parameter). We took $n=0.015 \mathrm{~m}^{-1 / 3} \mathrm{~s}$, which is typical for the natural bottom (sand, small pebbles).

As atmospheric forcing (Fig. 4), we used the data on the temporal and spatial wind velocity distribution at $10 \mathrm{~m}$ height, taken from the Climate Forecast System Reanalysis (CFSR) database (https://climatedataguide.ucar.edu/ climate-data / climate-forecast-system-reanalysis-cfsr; https://data.nodc.noaa.gov/cgibin/iso?id=gov.noaa.ncdc:C00765). It should be noted that the data on atmospheric pressure were not used in the calculations, since the atmospheric pressure gradient in the water area under study was small.

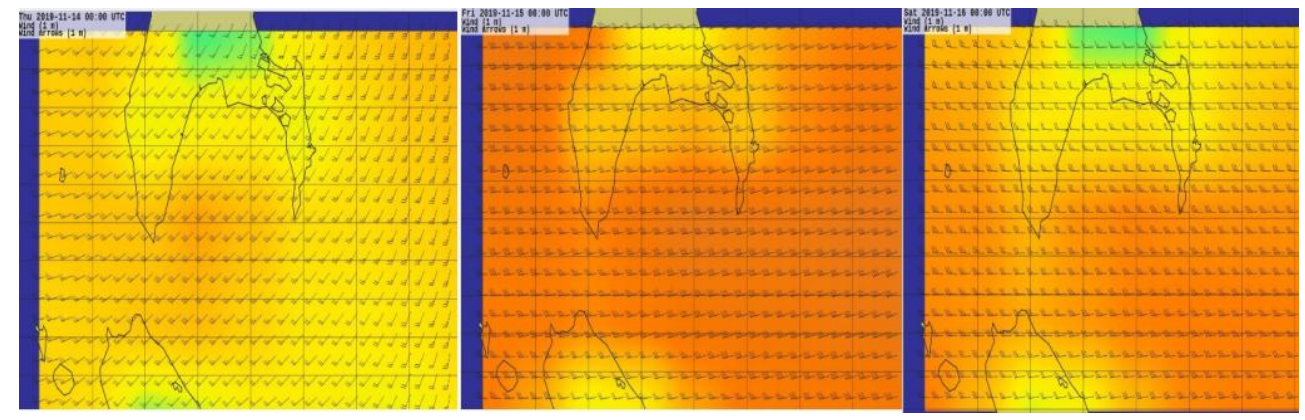

F i g. 4. Wind spatial distribution at the $10 \mathrm{~m}$ altitude during the period 14.11.2019-16.11.2019 (from left to right) based on the CFSR data

30-second Global Ocean Bathymetry (GEBCO30 Digital Atlas) was used for the simulations with the addition of more accurate coastal bathymetry of Aniva Bay, which was obtained from various sources. The Aniva Bay water area bathymetry was set with a step of about $150 \mathrm{~m}$. In order to calculate the wave runup, the embedded bathymetry of Korsakov area with a step of about $20 \mathrm{~m}$ was used. The calculated area is shown in Fig. 5. In the northern part of Aniva Bay, on the land, the boundary conditions of total reflection were set (vertical wall at $5 \mathrm{~m}$ depth). In the area of Korsakov, conditions that provided the wave rolling were set. In the southern part of the bay, the conditions for the free departure of waves from the water area were set.

The modeling was carried out for a period of three days. After 20 hours, the water level in the port rose by about $1.7 \mathrm{~m}$, the water began to subside only a day later. The water level rose most strongly in the southwestern part of Aniva Bay (Fig. 5). The calculated current velocities reached $2 \mathrm{~m} / \mathrm{s}$, which pose a significant danger to ships and coastal infrastructure. The analysis of distribution of water level variations over the entire modeling time $(72 \mathrm{~h})$ shows that the maximum water level elevations are concentrated in the northwestern part of Aniva Bay (Fig. 6). 


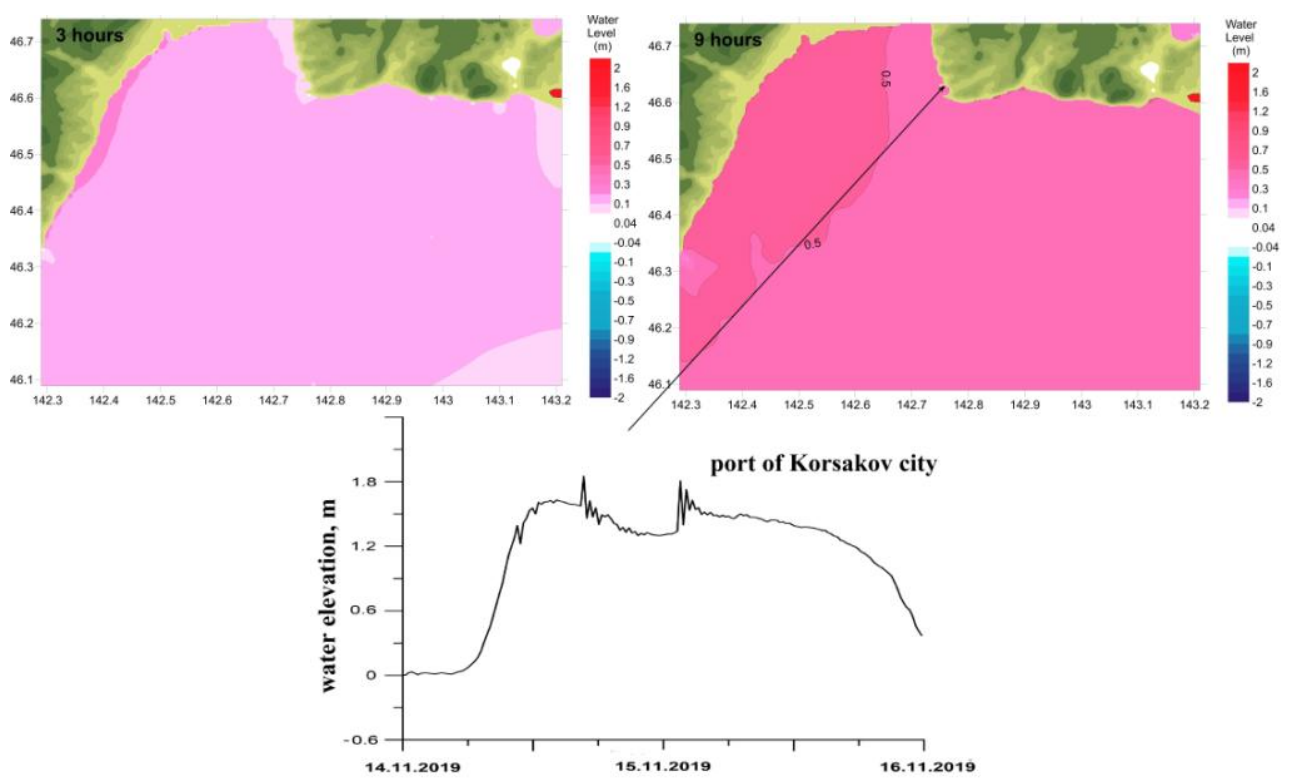

F i g. 5. Distribution of water surface displacements during the storm on November 15, 2019: in 3 (left) and 9 (right) hrs from its beginning. The lower figure shows the calculated mareogram for the port of Korsakov

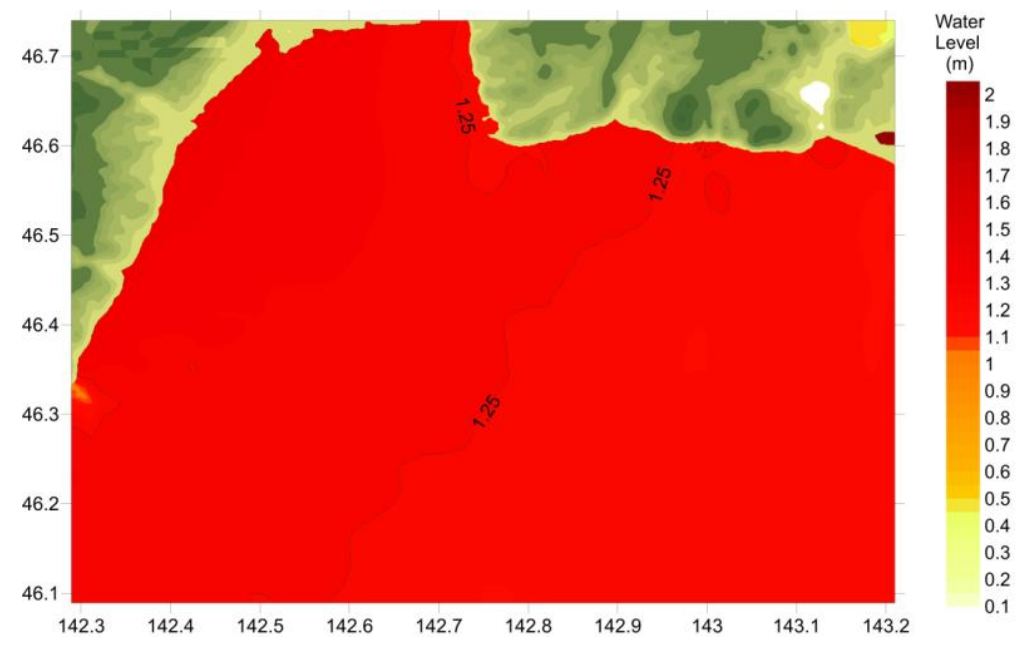

F i g. 6. Spatial distribution of the water level elevation maximums for $72 \mathrm{hrs}$ of simulation

The impact of the storm surge on the shore was modeled using nested grids only for the Korsakov area. The resulting distribution of storm surge heights along the coast is shown in Fig. 7. The maximum surge height is $1.7 \mathrm{~m}$, which is in good agreement with the field survey results. The width of the floodplain is $200 \mathrm{~m}$ from the shoreline and covers the port area. 

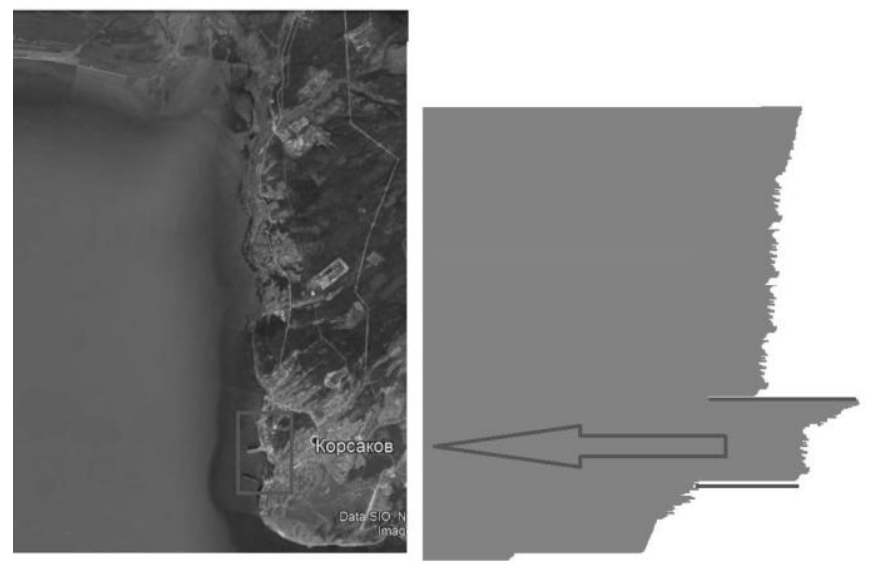

runup height, $\mathrm{m}$

F i g. 7. Distribution of surge heights along the coast. Rectangle marks the part where measurements were performed

It is of interest to calculate the impact of a storm surge on the simplest element of the port infrastructure - small-diameter round mounting support. When flowing around a vertical obstacle of small diameter, the hydrodynamic pressure can be expressed by the formula

$$
F_{h}=\frac{1}{2} \rho_{w} \mathrm{~g} D S
$$

where $\rho_{w}$ is a sea water density; $D$ is total water depth; $S$ is a cross-section area (towards the wave propagation direction).

A structure in a viscous flux is also affected by the drag force, which is approximated by the formula

$$
F_{f}=\frac{1}{2} \rho_{w} C_{D} u^{2} S
$$

where $C_{D}$ is a drag coefficient; $u$ is a velocity of current in the computational point with no regard to the structure.

From the ratio of two components of the forces affecting a single obstacle of small diameter, as can be seen from (4) and (5), we find the so-called "hydrodynamic parameter" [11]:

$$
H D=\frac{F_{f}}{F_{h}}=C_{D} \frac{u^{2}}{g D}=C_{D} \mathrm{Fr}^{2},
$$

proportional to the Froude number

$$
\operatorname{Fr}=\frac{u}{\sqrt{g D}} .
$$


The Froude number calculation demonstrates the ratio of the forces of impact on structures.

All the parameters listed above are integrated into the NAMI-DANCE software package. The results of calculating the squared Froude number for the Aniva Bay during the storm surge are shown in Fig. 8. They show that when the wave moves from the west, the port area and the adjacent territory of Korsakov will be subject to a very significant impact.

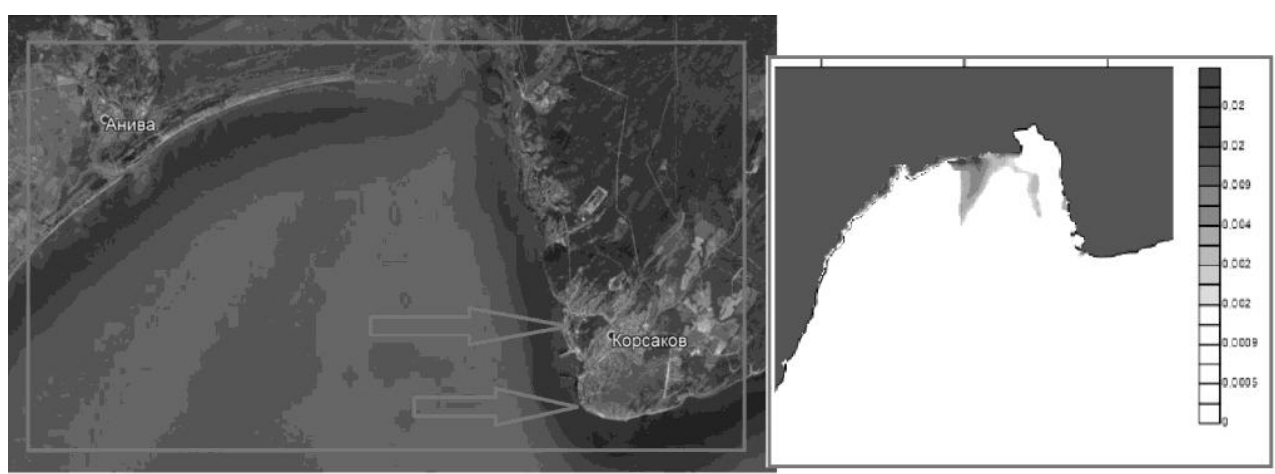

F i g. 8. Maximum values of the Froude number square for the storm on 15.11.2019 (arrows show its highest values on the coast of Korsakov city)

In [12], it is proposed to use the following characteristic, called the moment, to distinguish zones of force impact of waves on port facilities:

$$
M o=D u^{2}
$$

The calculated values of the moment (8) for the storm that took place on 15 November 2019 are given in Fig. 9. The spatial distribution of this characteristic is also evidence of the significant storm surge force impact on port structures.

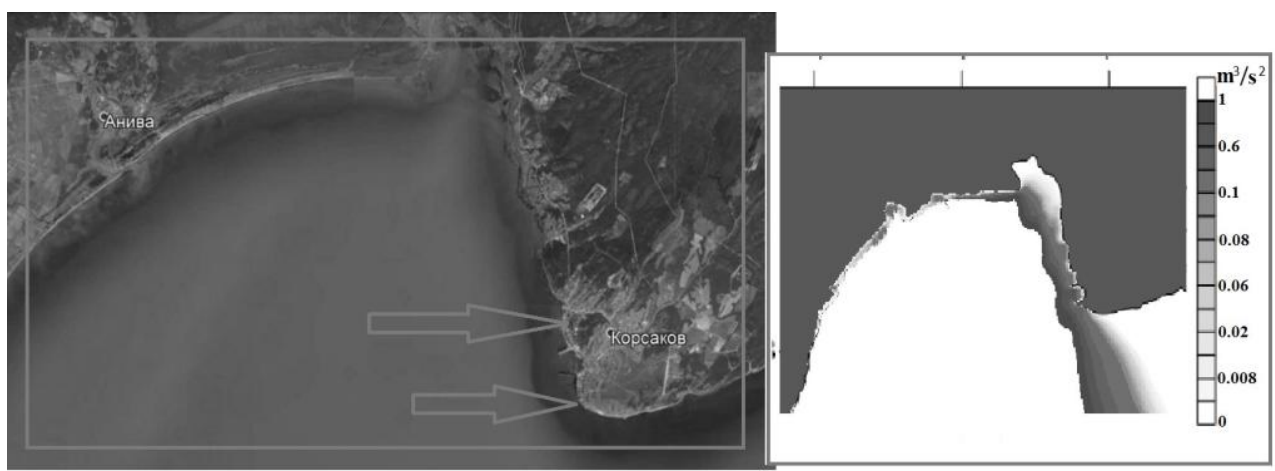

F i g. 9. Values of the moment $\left(\mathrm{m}^{3} / \mathrm{s}^{2}\right)$ for the storm on 15.11.2019 (arrows show the highest values on the coast of Korsakov city) 


\section{Conclusion}

On the basis of field measurements, an analysis of the consequences of storm surge that took place in the Korsakov area in the south of the Sakhalin on 15 November 2019 was carried out. Numerical modeling of this event was carried out within the framework of nonlinear shallow water equations using the NAMI$D A N C E$ computational complex. Storm conditions were modeled using the data on wind temporal and spatial distribution at $10 \mathrm{~m}$ height from the Climate Forecast System Reanalysis (CFSR) database. It was revealed that at wind velocity of up to $15 \mathrm{~m} / \mathrm{s}$ the storm surge height in the area of the Korsakov port was $1.7 \mathrm{~m}$, the width of the flooding zone reached $200 \mathrm{~m}$, which is fully consistent with the research results.

\section{REFERENCES}

1. Shevchenko, G.W., Lyubitsky, Yu.V. and Kato, L.N., 1994. [Manifestations of Storm Surges in the Southern Part of Sakhalin Island]. Yuzhno-Sakhalinsk: IMGG FEB RAS, 44 p. (preprint, in Russian).

2. Kato, J., Mis'kov, O.A. and Shevchenko, G.V., 2001. [Storm Surges on the Coast of Sakhalin Island in the Late Twentieth Century]. In: G. V. Shevchenko, ed., 2001. Dynamic Processes on the Shelf of Sakhalin and the Kuril Islands. Yuzhno-Sakhalinsk: IMGG FEB RAS, pp. 160-176 (in Russian).

3. Shevchenko, G.V., 1997. Statistical Features of Storm Water Masses Run up in South Part Sakhalin. Izvestiya Russkogo Geograficheskogo Obshestva, 129(3), pp. 94-107 (in Russian).

4. Kovalev, D.P., 2013. Extreme Negative Surge at the South-Eastern Coast of Sakhalin Island. Fundamentalnaya i Prikladnaya Gidrofizika, 6(1), pp. 52-57 (in Russian).

5. Fomin, V.V. and Ivanov, V.A., 2004. Numerical Modeling of Wind Emotion near the Tuzla Bar Island. In: MHI, 2004. Ekologicheskaya Bezopasnost' Pribrezhnykh i Shel'fovykh Zon i Kompleksnoe Ispol'zovanie Resursov Shel'fa [Ecological Safety of Coastal and Shelf Zones and Comprehensive Use of Shelf Resources]. Sevastopol: ECOSI-Gidrofizika. Iss. 10, pp. 233-242 (in Russian).

6. Fomin, V.V., Alekseev, D.V., Lemeshko, E.M. and Lazorenko, D.I., 2018. Simulation and Analysis of Sea Floods in the Don River Delta. Russian Meteorology and Hydrology, 43(2), pp. 95-102. https://doi.org/10.3103/S106837391802005X

7. Shul'ga, T.Ya., 2006. Simulation of Surge Phenomena in a Bounded Sea Basin. Physical Oceanography, (6), pp. 313-321. https://doi.org/10.1007/s11110-006-0035-8

8. Ivanova, A.A., Arkhipkin, V.S., Myslenkov, S.A. and Shevchenko, G.V., 2015. Modeling of Storm Surges in the Coastal Zone of the Sakhalin Island. Vestnik Moskovskogo Universiteta. Seriya 5, Geografiya, (3), pp. 41-49 (in Russian).

9. Zaytsev, A.I., Kurkin, A.A., Pelinovsky, E.N. and Yalciner, A., 2019. Computational NAMIDANCE Complex in the Problem of Tsunami Waves. Computational Continuum Mechanics, 12(2), pp. 161-174. doi:10.7242/1999-6691/2019.12.2.14 (in Russian).

10. Zaytsev, A., Kurkin, A., Pelinovsky, E. and Yalciner, A.C., 2019. Numerical Tsunami Model NAMI-DANCE. Science of Tsunami Hazards, 38(4), pp. 151-168. Available at: http://www.tsunamisociety.org/sthvol38n4y2019.pdf [Accessed: 10 July 2020].

11. Ozer, C. and Yalciner, A.C., 2011. Sensitivity Study of Hydrodynamic Parameters during Numerical Simulations of Tsunami Inundation. Pure and Applied Geophysics, 168(11), pp. 2083-2095. doi:10.1007/s00024-011-0290-6

12. Park, H., Cox, D.T., Lynett, P.J., Wiebe, D.M. and Shin, S., 2013. Tsunami Inundation Modeling in Constructed Environments: A Physical and Numerical Comparison of FreeSurface Elevation, Velocity, and Momentum Flux. Coastal Engineering, 79, pp. 9-21. doi:10.1016/j.coastaleng.2013.04.002 
About the authors:

Andrey I. Zaytsev - Leading Research Associate, Special Design Bureau for Marine Research Automation Tools of the Far Eastern Branch of the Russian Academy of Sciences, (25 Gor'kogo str., Yuzhno-Sakhalinsk, 693023, Russian Federation), Dr. Sci. (Phys.-Math.), ORCID ID: 0000-0002-1383-363X, ResearcherID: A-1772-2014, aizaytsev@ mail.ru

Efim N. Pelinovsky - Chief Scientist, Institute of Applied Physics of Russian Academy of Sciences (46 Ulyanova str., Nizhny Novgorod, 603950, Russian Federation), Dr. Sci. (Phys.-Math.), Professor, ORCID ID: 0000-0002-5092-0302, ResearcherID: I-3670-2013, pelinovsky@ gmail.com

Gozde Guney Dogan - Assistant, Middle East Technical University, Department of Civil Engineering (K5 Building No: K5-014, Ankara, 06800, Turkey), ORCID ID: 0000-0002-8638-8792, gguneydogan@gmail.com

Bora Yalciner - Postgraduate, Middle East Technical University, Department of Civil Engineering (K5 Building No: K5-014, Ankara, 06800, Turkey), ORCID ID: 0000-0003-1642-9509, yalciner.bora@metu.edu.tr

Ahmet Cevdet Yalciner - Ph. D., Middle East Technical University, Department of Civil Engineering (K5 Building No: K5-014, Ankara, 06800, Turkey), Dr. Sci., Professor, ORCID ID: 0000-0001-8947-7523, yalciner@ metu.edu.tr

Andrey A. Kurkin - Pro-rector for Research, Head of Applied Mathematics Department, Head of the Laboratory for Modeling Natural and Man-Made Disasters, Nizhny Novgorod State Technical University n. a. R. E. Alekseev (24 Minina str., Nizhny Novgorod, 603950, Russian Federation), Dr. Sci. (Phys.-Math.), Professor, ORCID ID: 0000-0003-3828-6406, ResearcherID: A-1972-2014, aakurkin@gmail.com

Alexander A. Moskvitin - Junior Research Associate, Special Design Bureau for Marine Research Automation Tools of the Far Eastern Branch of the Russian Academy of Sciences (25 Gor'kogo str., Yuzhno-Sakhalinsk, 693023, Russian Federation), ameleouth@ mail.ru

Contribution of the co-authors:

Andrey I. Zaytsev - numerical modeling, general scientific supervision of research, discussion of the research results, analysis and synthesis of research results, formulation of conclusions, editing and addition of the article text, development and debugging of a computer program for solving a problem

Efim N. Pelinovsky - general scientific supervision of research, formulation of the goals and objectives of the study, discussion of the research results, analysis and synthesis of research results, formulation of conclusions, writing annotations, critical analysis and revision of the text, editing and addition of the article text

Gozde Guney Dogan - selection and justification of numerical methods for solving equations, qualita-tive and quantitative analysis of the results, processing and description of the research results, analysis of materials on the research topic, reference review on research, reference review of foreign sources, computer works

Bora Yalciner - numerical modeling, processing and description of the research results, development and debugging of a computer program for solving a problem, computer works

Ahmet Cevdet Yalciner - general scientific supervision of research, numerical modeling, formulation of the goals and objectives of the study, discussion of the research results, analysis and synthesis of research results, formulation of conclusions, writing annotations, critical analysis and revision of the text, editing and addition of the article text

Andrey A. Kurkin - analysis of materials on the research topic, reference review on research, reference review of foreign sources, critical analysis and revision of the text, editing and addition of the article text

Alexander A. Moskvitin - field surveys, sea level measurements, flooding area measurements, preparing figures for a paper

The authors have read and approved the final manuscript.

The authors declare that they have no conflict of interest. 